DOI 10.5216/ia.v45i3.64358

\title{
A IMPLANTAÇÃO DO GRUPO ESCOLAR NO MUNICÍPIO DE CRUZEIRO DO SUL/ACRE
}

\author{
MARIA IRINILDA DA SILVA BEZERRA \\ ADEMÁrCIA LOPES DE OLIVEIRA COSTA \\ Universidade Federal do Acre/Campus Floresta (UFAC), Cruzeiro do Sul, Acre, Brasil.
}

\begin{abstract}
Resumo: O presente estudo tem como objetivo analisar a implantação do grupo escolar Barão do Rio Branco no município de Cruzeiro do Sul - Acre, ressaltando as contribuições da instituição para o desenvolvimento sociocultural da população local. Utilizou-se a abordagem qualitativa, por meio das pesquisas bibliográfica, documental e de campo, com o uso da entrevista semiestruturada. Os resultados evidenciam que a implantação do grupo escolar no município de Cruzeiro do Sul teve como meta principal atender à demanda educacional da região, que sofria com a inexistência de instituições que oferecessem condições físicas e pedagógicas à população em idade escolar. Ainda assim, conclui-se que esta instituição sofreu o descaso das autoridades do Estado, quanto à falta de materiais didáticos e pedagógicos.
\end{abstract}

Palavras-chave: História da educação. Grupo escolar. Ensino primário.

\section{INTRODUÇÃO}

De São Paulo para outras regiões do Brasil, no final do século XIX, presenciou-se um movimento de expansão e melhorias do sistema escolar, sobretudo por meio da criação dos grupos escolares. A reforma Caetano de Campos, realizada em São Paulo, nos anos de 1890 a 1896, foi a grande idealizadora deste modelo escolar que pretendia tornar clarividente o ideário educativo dos republicanos que assumiram o controle do país naquele período. As edificações escolares foram ganhando o estilo monumental. Logo, podemos dizer que os grupos eram instituições de ensino primário que quebravam com a estrutura de escolas isoladas da época, tanto no que diz respeito à estrutura física como pedagógica.

Os grupos escolares, que normalmente eram construídos nos centros urbanos, funcionavam de forma seriada, possuíam uma estrutura administrativa e pedagógica, com várias turmas funcionando no mesmo local e com professor próprio. Nessas condições, essas instituições se consolidaram como o modelo de escolas seriadas republicanas, com espaços e entradas distintas para meninos e meninas.

Nesse cenário se insere o presente estudo, que pretende suscitar uma reflexão sobre os grupos escolares, o que certamente contribui para o conhecimento da história da educação brasileira e, mais especificamente, para a história escolar do município de Cruzeiro do Sul - Acre. 
Nessa direção, esta investigação tem como objetivo analisar a implantação do grupo escolar Barão do Rio Branco no município de Cruzeiro do Sul - Acre, ressaltando as contribuições da instituição para o desenvolvimento sociocultural da população local. Procuramos observar de que forma a herança educacional do grupo escolar contribuiu para a construção dos tempos/espaços escolares e para a cultura escolar do referido município. Sabemos que o grupo escolar Barão do Rio Branco, constituiu-se como um avanço essencial para que a educação da população local pudesse ser incentivada, repensada e aos poucos alcançasse o salto necessário à qualidade do ensino.

Assim, esta pesquisa nos permitiu refletir sobre as seguintes indagações: Como se deu o ensino no grupo escolar Barão do Rio Branco? Qual a importância desta instituição na escolarização da população cruzeirense? Quais os maiores desafios enfrentados pela referida instituição? Como o grupo escolar se organizou didaticamente no município de Cruzeiro do Sul?

Pesquisar sobre a constituição dos grupos escolares pressupõe um aporte metodológico que contemple a complexidade do tema. Por isso, esta é uma pesquisa de cunho qualitativo e baseou-se no método histórico, utilizando como técnica de coleta de dados a entrevista semiestruturada e a análise documental de fontes primárias dos arquivos de secretaria da instituição, tais como atas, boletins, fichas individuais, provas e outros documentos históricos ou pedagógicos. A entrevista semiestruturada foi realizada com seis (6) professoras que atuaram na instituição pesquisada.

Segundo Ludke $(1986$, p. 11) "a pesquisa qualitativa supõe o contato direto e prolongado do investigador com o ambiente e a situação que deve ser pesquisada [...]". Este tipo de abordagem trabalha com valores, crenças, hábitos, atitudes, representações e opiniões, buscando aprofundar a complexidade de fatos e processos particulares e específicos a indivíduos e grupos.

A pesquisa bibliográfica é compreendida como aquela em que se faz uso de material já publicado, como livros, revistas, teses, dissertações etc. (LUDKE, 1986). No que diz respeito à análise documental, é uma técnica de pesquisa muito relevante, pois possibilita ao pesquisador desvendar aspectos de uma dada realidade por meio de documentos produzidos e preservados pelos próprios sujeitos que fizeram ou fazem parte desta realidade, possibilitando um aprofundamento maior sobre o objeto de estudo, principalmente quando se refere a instituições educacionais. Nestes casos, as fontes escritas e os documentos oficiais são quase sempre a base do trabalho de investigação e ajudaram a constituir a história da instituição.

Quanto à entrevista semiestruturada, é uma técnica em que o pesquisador realiza questionamentos ao colaborador com o objetivo de obter os dados que interessam à pesquisa. É um meio de interação social, forma de diálogo, em que uma das partes busca colher dados e a outra se apresenta como fonte de informação. Possibilita que as informações sejam analisadas qualitativamente, portanto se constitui em um recurso eficiente para obtenção de dados referentes ao comportamento dos sujeitos nas realidades sociais. Vale ressaltar que, neste estudo, optou-se por utilizar de maneira indireta os dados advindos das entrevistas. Leitão (2005) considera a entrevista um dos métodos mais utilizados na pesquisa qualitativa, pois têm a vantagem da interação 
direta entre o investigador e os sujeitos participantes, bem como a possibilidade de valorização da memória no estudo do passado.

Este estudo está organizado da seguinte maneira: primeiramente, pela introdução ora apresentada, contendo o tema e o objetivo da pesquisa; em seguida apresentamos o referencial teórico, no qual dissertamos e problematizamos sobre a história dos grupos escolares no Brasil; dando seguimento, apresentamos procedimento metodológico adotado; na sequência, os resultados e discussões, apontando os elementos que se entretecem na constituição do grupo escolar no município de Cruzeiro do Sul - Acre. Para encerrar, apresentamos as considerações finais com os achados da pesquisa.

\section{GRUPOS ESCOLARES: REMEMORANDO A HISTÓRIA}

No Brasil, a educação escolarizada sempre sofreu problemas de falta de estrutura física, de recursos humanos e pedagógicos. Estas lacunas deixadas pelo poder público em termos de escolarização foram permeadas por momentos ambíguos, entrelaçados ora pelo descaso, ora pelo interesse em sanar tais problemas. Interesse, muitas vezes demandado pela população que sofria os efeitos de tais deficiências pedagógicas, outras vezes, o interesse provinha do próprio Estado e de seus idealizadores que viam na educação uma arma para moralizar, civilizar e qualificar a população com vistas a atuar nos vários setores econômicos e políticos da sociedade.

Na perspectiva de Souza (2004, p. 113), "a criação dos grupos escolares foi um marco da modernização educacional paulista". Tendo como foco a educação primária, essas instituições tornaram-se o elemento principal no processo de civilização da nação no período de implantação da República no Brasil. Assim, mudar o sistema de ensino no país era essencial para diminuir o caos em que se encontrava a educação no período. Participavam dessas discussões os políticos, os grandes proprietários rurais e os intelectuais, que debatiam constantemente os problemas econômicos do país e viam na educação a salvação da nação diante da situação de atraso social e, automaticamente, econômico e cultural.

Após a implantação da República, os políticos e intelectuais, que estavam à frente do movimento político, decidiram implantar um modelo de escola que se configurasse como moderna e pedagogicamente adequada aos novos tempos que se instalavam. A ideia era romper com o atraso escolar, símbolo do império. O modelo pensado foi então os grupos escolares, instituições escolares que se apresentavam com uma estrutura física e pedagógica capaz de romper com o modelo de instituição improvisada que funcionava em locais diversos, como feiras, sacristias, casas de professores etc., como era comum nos tempos do império. Nesse entorno, Vidal e Faria Filho (2005, p. 42-43) destacam que

[...] a construção de espaços adequados para o ensino, bem como a definição de tempos de aprendizagem, estava relacionada não apenas à possibilidade de a escola vir a cumprir as funções sociais que lhe foram crescentemente delegadas, mas, também, à produção da singularidade da instituição escolar e da cultura que Ihe é própria. [...] sua extensão estava intimamente relacionada à distribuição e a utilização dos tempos escolares, à constituição dos 
métodos pedagógicos e á [sic] organização de turmas, classes e espaços escolares.

No movimento de consolidação dos grupos escolares, observou-se o surgimento de uma nova cultura escolar, isto é, o estabelecimento de uma organização administrativa e didático-pedagógica nas instituições de ensino, a fim de tornar-se um novo paradigma na produção e circulação dos saberes pedagógicos, na apropriação de modelos culturais, históricos, sociais e políticos. Nestes termos, o modelo dos grupos escolares com seu sistema de graduação se consolidou e se expandiu, interferindo na cultura escolar, deixou um importante legado nas instituições de ensino, no qual podemos destacar alguns: a seriação, a organização administrativa e didáticopedagógica, a estrutura física, entre outros. Sobre esta questão Souza (2004, p. 113) destaca:

Os grupos escolares foram criados no estado de São Paulo em 1893, a partir de reuniões de escolas isoladas agrupadas pelas proximidades, ficando obrigados a adotar o tipo de organização e método de ensino das escolas modelos do estado. À medida que tais escolas-modelo foram consolidando-se e os grupos escolares começaram a funcionar nos centros urbanos, eles foram diferenciando-se cada vez mais das outras escolas primárias existente no estado.

Nesse entendimento, os grupos escolares do Estado de São Paulo, criados no contexto da reforma Caetano de Campos, se organizaram a partir da junção de escolas isoladas e adotavam o modelo de organização didática e pedagógica das Escolas Modelos que funcionavam no estado. Para agrupar as escolas isoladas que formariam os grupos escolares, o governo adotava o critério da proximidade.

De São Paulo, essas instituições modelares se expandiram para vários estados brasileiros, com a perspectiva de transmitir, por meio da instituição escolar, os ideais morais republicanos. Para Carvalho (2003, p. 225), podemos chamar de "modelo escolar paulista" o agrupamento de investimentos colocados em prática pelos republicanos paulistas no intuito de consolidar um novo modelo de ensino, pautado na sua visibilidade em dois sentidos: "na lógica que presidiu a sua institucionalização e na força exemplar que passa a ter nas iniciativas de remodelação escolar de outros estados" (CARVALHO, 2003, p. 225).

O avanço da ciência e o desenvolvimento de saberes científicos contribuíram para o surgimento de um discurso de defesa da construção de espaços específicos para a escola e para a educação de crianças e jovens. Nesta perspectiva, ao mesmo tempo em que os higienistas elaboravam uma contundente crítica às péssimas condições das moradias e dos demais prédios para a saúde da população em geral, acentuavam de maneira contundente o mal que as instalações escolares inadequadas causariam à saúde infantil.

No entorno do discurso de que a inexistência de espaços e materiais higienicamente concebidos era prejudicial à saúde e à aprendizagem dos alunos, os grupos escolares se colocavam como o espaço planejado para a atividade escolar, de 
modo a garantir, ao mesmo tempo a aprendizagem e a saúde dos escolares. Souza (1998) aponta estas instituições como responsáveis por construir um novo modelo de organização e de espaço de ensino. A autora ressalta que,

A criação dos grupos escolares surge portanto no interior do projeto político republicano de reforma social e de difusão da educação popular - uma entre as várias medidas de reforma da instrução no Estado de São Paulo implementadas a partir de 1890. A implantação dessa nova modalidade escolar teve implicações profundas na educação pública do Estado e na história da educação do país (SOUZA, 1998, p. 30).

Os grupos escolares, enquanto padrão de organização do espaço-tempo e dos aspectos didático-pedagógico, representaram uma inovação significativa, uma vez que contribuíram para a racionalização dos esforços didáticos e, consequentemente, para a construção da identidade escolar. Como afirma Souza (1998, p. 28), "mais do que um direito do cidadão, a educação foi concebida e propagandeada como uma necessidade e, sobretudo, como um dever de cada homem do povo, pois ela significava o credenciamento para a participação no regime republicano", ou seja, a reforma social que os republicanos pretendiam imprimir no país passava pela reforma da educação. Só assim a nação se modernizaria e alcançaria os níveis de desenvolvimento dos países europeus. Sobre estas mudanças e inovações pedagógicas, necessárias à modernização social, a autora acrescenta que a implantação dos grupos escolares como novo padrão de ensino primário "[...] ajudou a produzir uma nova cultura escolar, repercutiu na cultura da sociedade mais ampla e encarnou vários sentidos simbólicos da educação no meio urbano, entre eles a consagração da República" (SOUZA, 1998, p. 30).

De acordo com a autora esses grupos escolares modificaram significativamente a cultura escolar no Brasil, implementando inovações na forma de organização das instituições escolares através da organização seriada das classes, da utilização racionalizada do tempo e dos espaços, bem como por meio do controle sistemático do trabalho das professoras, entre outros aspectos implementados.

Assim, pouco tempo depois de suas primeiras construções, os grupos escolares, ofereciam significativas diferenças em relação à organização da escola isolada, que predominava no período. Apresentando-se como referência básica para a organização escolar, além das inovações mencionadas, como: a graduação ou seriação das turmas, o melhor aproveitamento do tempo e espaço escolar e o controle das ações desempenhadas pelos professores no espaço institucional, esses grupos também inovaram na invenção da figura do diretor escolar, que garantia a efetivação de todos esses aspectos por meio de um trabalho de fiscalização e acompanhamento constante das atividades desempenhadas no interior da instituição.

Nas palavras de Souza (1998), o diretor se constituía numa autoridade do Estado, no porta-voz entre a escola e o governo. E assim como ocorria com os inspetores de ensino, a escolha para o cargo de diretor se baseava na indicação do governador, sendo que esse cargo geralmente era ocupado por professores com diploma da escola Normal do Estado e/ou com comprovada experiência na docência. Sobre a identidade deste profissional, a autora acrescenta: 
O diretor era visto como uma autoridade do governo. [...] A autoridade do diretor foi construída sobre a encarnação do poder do Estado, como legítimo representante do governo no âmbito da sua competência. Dessa forma, ele deveria ser considerado pelos professores, alunos e comunidade local (SOUZA, 1998, p. 78).

Com todas essas condições, a procura pelo grupo escolar aumentava, tanto por parte dos alunos e pais, quanto dos professores. Os alunos e pais preferiam esta instituição porque ela funcionava em prédio monumental, o que garantia bem-estar e comodidade em suas instalações. A procura por uma vaga ocorria por todos os aspectos positivos que essa instituição apresentava se comparada à estrutura das demais escolas da época. Ter o(a) filho(a) matriculado(a) em um grupo escolar era garantia não apenas de uma boa educação escolar, mas também de status social. Porém, mesmo depois da implantação dos grupos escolares, o ensino público daquele período continuava sofrendo de muitos problemas em todo o país, tais como a carência de vagas e de escolas e também "a deficiência das escolas isoladas destacando sua inferioridade administrativa e técnico-pedagógica em relação aos grupos escolares" (SOUZA, 1998, p. 74). A exceção ficava mesmo por conta dos grupos escolares, como mencionado anteriormente. Quanto aos docentes, preferiam lecionar nesses ambientes, logicamente pela oferta de melhores salários e de condições de trabalho, além do status social que tais instituições proporcionavam, principalmente, às mulheres. Para Souza (1998, p. 62), "o magistério deixava de ser uma desventura e tornava-se uma profissão digna, reconhecida e edificante. O grupo escolar contribuiu para a reafirmação desse status, constituindo-se em um campo de trabalho e de produção de identidades profissionais".

Diante dos aspectos acima destacados, podemos afirmar que os grupos escolares deixaram, no Brasil inteiro, uma contribuição inegável para a consolidação da cultura escolar e sua história precisa ser estudada para que possamos compreender mais profundamente a história da educação no Brasil.

Nessa direção, cada grupo escolar, dependendo da região onde foi instalado, apresentou características próprias. Estas especificidades abarcam não apenas o lado positivo que estas instituições apresentaram Brasil a fora, mas também as lacunas que deixaram, decorrentes do descaso das autoridades do Estado, que permitiram faltar materiais didáticos, pedagógicos e infraestrutura adequada. Desse modo, o estudo aprofundado de cada instituição, com sua realidade cotidiana, seus impasses e dificuldades de funcionamento nos levam a conhecer não só a história do ensino primário no Brasil República, mas também a história da educação no Brasil.

\section{O GRUPO ESCOLAR BARÃO DO RIO BRANCO}

O grupo escolar Barão do Rio Branco foi implantado em Cruzeiro do Sul-AC visando oportunizar o desenvolvimento cultural e social da realidade do município. Esta instituição foi o primeiro grupo escolar construído em Cruzeiro do Sul e estava localizado à Rua Rego Barros, n 107, no centro da cidade. Foi construído em 1908 na gestão do prefeito Dr. Antonio Bueno de Andrade e funcionava inicialmente como liceu, o Liceu Afonso Pena, conhecido também como "Casa Paterna ou Casa do Prefeito do 
Juruá". Era um casarão com térreo, onde funcionava ao mesmo tempo uma escola primária e a casa do prefeito. Este Liceu foi pensado para tornar-se escola modelo no município, mas, por falta de recursos, pouco tempo depois de sua fundação foi fechado.

Em 1911, na gestão do Capitão Julio Francisco de Serpa, a instituição voltou a funcionar, recebendo o nome de "Grupo Escolar Barão do Rio Branco" em homenagem a José Maria da Silva Paranhos Júnior, O Barão do Rio Branco.

Notamos que o município de Cruzeiro do Sul, nas primeiras décadas do século XX, apresentava sérias limitações em relação ao seu sistema público de ensino. Esses problemas persistiam mesmo após a criação e funcionamento do grupo escolar Barão do Rio Branco, isso resultou na necessidade de criar novas escolas, novos grupos. No Brasil, a ideia de que a construção de prédios específicos para o ensino e a aprendizagem era uma necessidade para se atingir o maior número de alunos com as benesses escolares surgiu no final do século XIX, assim como pontua Vidal e Faria Filho (2005, p. 50),

[...] foi-se, paulatinamente, reforçando a representação de que a construção de prédios específicos para a escola era imprescindível a uma ação eficaz junto às crianças, indicando, assim, o êxito daqueles que defendiam a superioridade e a especificidade da educação escolar diante das outras estruturas sociais de formação e socialização como a família, a igreja e, mesmo, os grupos de convívio.

Ao indagar uma professora participante deste estudo sobre a importância do grupo escolar para a região, ela ressaltou que o município era carente de escolas que pudessem oferecer à população a oportunidade de se escolarizar, e a criação do grupo escolar Barão do Rio Branco proporcionou à sociedade cruzeirense uma conquista muito importante neste sentido. Porém, este grupo não apresentava vagas suficientes para atender à demanda local, assim, muitos não conseguiam vaga para estudar na instituição. Todavia, de acordo com os relatórios de matrículas, mesmo com a grande demanda por matrículas, havia evasão escolar de muitos alunos, fato que ocorria, sobretudo, por não conseguirem acompanhar os estudos nos primeiros anos do primário.

Isso acontecia, de acordo com uma professora participante da pesquisa, porque o nível de cobrança dos estudos no grupo era muito mais elevado do que nas demais escolas do município. Embora os primeiros anos da República tenham proporcionado, nas palavras de Souza (1998, p. 82), "o crescimento do número de escolas e alunos", anunciando "a efetivação dos ideais de democratização do ensino, a alta seletividade da escola primária comprometia esses mesmos ideais". Ainda, nesta análise, a autora acrescenta que, para a maioria dos alunos das classes populares, a passagem pela escola significava um período relativamente curto, pois, a exigência nos estudos era grande. Dessa forma, Souza (1998, p. 85) acrescenta que,

A seletividade da escola primária encontra-se, pois, no limiar entre os propósitos propugnados e as condições reais de atendimento às camadas populares. [...]. A manutenção de um sistema de ensino tão seletivo no grau inicial pode ser entendido com a potencialização 
de um projeto político-cultural de uma sociedade altamente hierarquizada.

Verificamos no relatório de matrícula que a profissão dos pais dos alunos do grupo escolar Barão do Rio Branco era diversa, tais como: motorista, seringalista, professor, doméstica, comerciário, agricultor, comerciante, seringueiro, militar, carpinteiro, bancário, diarista, pedreiro, pescador, servente, padeiro e missionário. A clientela atendida pela escola era procedente de vários municípios, como Cruzeiro do Sul, Tarauacá, Feijó e também vilas, hoje municípios, como Porto Walter, Guaraní, Marechal Thaumaturgo e Rodrigues Alves. Além de atender alunos oriundos dos seringais Adélia Juruá, Tejo, Liberdade, Belém-Juruá, Porto Valter, Novo Acre e outros. Podemos averiguar que o grupo escolar Barão do Rio Branco, em parte, destoava de muitos grupos escolares espalhados pelos Brasil, uma vez que a história destas instituições foi marcada pelo atendimento às elites locais, enquanto que no grupo ora estudado, as profissões dos pais indicam que, muitos alunos que ali estudavam, pertenciam às classes populares.

Com relação ao espaço escolar, notamos que a instituição possuía um ambiente melhor estruturado do que as demais escolas do período, mas, mesmo assim, ainda tinha algumas limitações em relação às necessidades pedagógicas dos alunos, tais como: faltava quadra para esportes, biblioteca etc. Sobre a política de construção dos grupos escolares, destacamos que o tempo e o espaço escolar se mostraram necessários ao desenvolvimento da escola moderna e graduada. Desse modo, os antigos espaços ocupados pelas escolas, como sacristias, casas de professores e espaços públicos emprestados para as atividades escolares, cederam lugar para a monumentalidade arquitetônica que seguiam padrões higiênicos internacionais. Nessa direção, Souza (1998, p. 123) esclarece que:

\footnotetext{
O edifício-escola deveria exercer, portanto, uma função educativa no meio social. Além disso, estabelecer a correspondência entre a importância da escola e o espaço ocupado. [...] Por isso, podemos dizer que a escola como lugar define-se juntamente com a constituição do espaço social e cultural da escola. A noção de lugar pressupõe a construção do espaço e sua ocupação e utilização; permite compreender a estrutura física do lugar nos limites da dimensão sociocultural [...] Os grupos escolares foram os estabelecimentos de ensino mais representativos dessa conformação de escola como lugar.
}

Podemos notar que, embora os grupos escolares tenham cumprido, no Brasil todo, uma importante função social, nem todos possuíam infraestrutura monumental e nem mesmo material didático com qualidade e em quantidade suficiente para atender às demandas pedagógicas e aplicar os métodos modernos de ensino que a época preconizava. Sobre este aspecto, uma das professoras participantes afirmou que o espaço da escola era organizado com carteiras que abriam e fechavam, parecidas com malas. A participante afirmou ainda que o espaço das salas de aula era suficiente para a 
quantidade de alunos, mas a escola tinha poucos materiais didáticos, basicamente o quadro de giz, o giz e alguns cartazes.

Na visão de Carvalho (2003), fez parte da política desse período a construção de edificações escolares monumentais. Os prédios eram construídos com base em uma arquitetura que adotava os princípios indicados pelos higienistas, portanto deveriam apresentar salas de aula com boa circulação de ar, iluminação suficiente para o estudo e mobiliário adequado ao físico do aluno. No que diz respeito à carga horária do currículo de $1^{\circ}$ grau, era dividida da seguinte forma:

Tabela 1. Séries e disciplinas

\begin{tabular}{|c|c|c|c|c|}
\hline \multirow{8}{*}{ DISCIPLINAS } & 1a Série & 2a Série & $3^{a}$ Série & $4^{a}$ Série \\
\hline & $\begin{array}{c}\text { Comunicação e } \\
\text { expressão }\end{array}$ & $\begin{array}{l}\text { Comunicação e } \\
\text { expressão }\end{array}$ & $\begin{array}{c}\text { Comunicação e } \\
\text { expressão }\end{array}$ & $\begin{array}{c}\text { Comunicação e } \\
\text { expressão }\end{array}$ \\
\hline & $\begin{array}{l}\text { Língua } \\
\text { portuguesa }\end{array}$ & $\begin{array}{l}\text { Língua } \\
\text { portuguesa }\end{array}$ & $\begin{array}{c}\text { Língua } \\
\text { portuguesa }\end{array}$ & $\begin{array}{l}\text { Língua } \\
\text { portuguesa }\end{array}$ \\
\hline & $\begin{array}{l}\text { Educação } \\
\text { Artística }\end{array}$ & $\begin{array}{l}\text { Educação } \\
\text { Artística }\end{array}$ & $\begin{array}{l}\text { Educação } \\
\text { Artística }\end{array}$ & $\begin{array}{c}\text { Educação } \\
\text { Artística }\end{array}$ \\
\hline & Educação física & Educação física & Educação física & Educação física \\
\hline & Integração Social & Integração Social & Integração Social & Integração Social \\
\hline & Ciências & Ciências & Ciências & Ciências \\
\hline & $\begin{array}{c}\text { Ciências Física e } \\
\text { Biológica }\end{array}$ & $\begin{array}{c}\text { Ciências Física e } \\
\text { Biológica }\end{array}$ & $\begin{array}{c}\text { Ciências Física e } \\
\text { Biológica }\end{array}$ & $\begin{array}{c}\text { Ciências Física e } \\
\text { Biológica }\end{array}$ \\
\hline & Matemática & Matemática & Matemática & Matemática \\
\hline
\end{tabular}

Observando os livros de ata de matrículas, no grupo escolar Barão do Rio Branco, vimos que a matrícula era feita no início do ano. Em 1978, por exemplo, na $1^{a}$ série, foram 106 alunos matriculados, divididos em três salas; na 2a série tinha 105 alunos em três salas; na $3^{a}$ série 71 alunos foram matriculados em duas salas; e na $4^{\text {a }}$ série 65 alunos estudaram em duas salas, totalizando 347 alunos em 10 salas. A matrícula era feita através dos responsáveis, obedecendo à ordem alfabética. No livro de ata ficava registrado o nome do aluno, sexo, endereço, idade, data de nascimento e número do registro. Além de constar se era aluno novo na escola ou repetente e, por último, constava o nome e a profissão dos pais. Após a matrícula inicial, se restassem vagas, havia um prazo para uma nova matrícula. O aluno não precisava fazer nenhum exame para entrar na escola, mas, sim, para ser promovido de ano.

De acordo com o livro de Atas de promoção de alunos do grupo escolar Barão do Rio Branco, de 1919 a 1947, o registro da promoção dos alunos era feita por série, da $1^{\text {a a }} 4^{\mathrm{a}}$, separando-os por seção masculina e feminina. As atas registravam os alunos que foram matriculados em cada ano, os que foram eliminados no decorrer dos semestres, ou seja, as desistências, e aqueles em condições de prestarem exame à "classe imediata em adiantamento". Após esses números, registravam-se o nome dos alunos/as que prestaram os exames e, por fim, a assinatura da banca examinadora.

Os números demonstram que a reprovação no grupo escolar Barão do Rio Branco era muito grande, sendo que a maioria dos alunos matriculados era reprovada nos exames finais. Como elucidamos anteriormente, era comum a prática de reprovação 
nos grupos escolares por conta do nível de exigência que os estudos naquelas instituições demandavam.

A partir do ano 1926, não observamos mais a separação dos alunos por sexo, visto que o registro passou a ser feito em uma única ata, contendo a promoção obtida por ambos os sexos. A separação por sexo era uma prática comum para o período, assim sendo, a identificação da seção masculina e feminina não se restringia ao livro de ata, mas fazia parte da dinâmica do grupo escolar. Arriscamos afirmar que não apenas nos grupos escolares, mas nas demais instituições educativas do município havia a rejeição ao princípio da coeducação. Bezerra (2010, p. 93), em sua dissertação de mestrado sobre a Escola Normal Regional de Cruzeiro do Sul, destaca que "quando as Escolas Normais foram sendo facultadas às mulheres, a administração da instrução pública das províncias ou estados foram inventando diferentes estratégias para impedir a co-educação." A autora destaca ainda que: "As escolas normais do início do século XIX não eram partidárias desse preceito, mas ainda na virada do século, boa parte dessas instituições já ofereciam atendimento misto" (BEZERRA, 2010, p. 111).

Pelos dados coletados, obtivemos informações sobre os resultados dos exames de promoção, no qual verificamos que os alunos recebiam conceitos de aprovados com distinção, aprovado plenamente, aprovado simplesmente ou reprovados. Estes conceitos eram comuns nas instituições escolares nas décadas iniciais do século $\mathrm{XX}$, não só no município de Cruzeiro do Sul, como em outras regiões do país.

Bezerra (2010, p. 152), ao estudar os mecanismos avaliativos empregados no Curso Normal Regional de Cruzeiro do Sul a partir da década de 1940, afirma que "A Escola qualificava os alunos nos testes da seguinte forma: aprovado com distinção, aprovado plenamente, aprovado simplesmente e reprovado". Galvão (2001, p. 133), em estudo nas escolas da região açucareira baiana, (1890 a 1920), observou esse mesmo tipo de avaliação, quando "[...] no final do ano, realizavam-se os exames [...] que atribuíam aos alunos conceitos de reprovado, aprovado simplesmente, aprovado plenamente e aprovado com distinção e louvor". Para a autora tais conceitos simbolizavam a função classificatória da escola e podiam interferir no sucesso da vida estudantil e até profissional dos alunos.

Outros autores também fazem alusão, em seus estudos sobre as formas de classificar os alunos no início do século XX. Galvão (2001), ao pesquisar uma escola primária do período de 1890 a 1920, identificou o mesmo tipo de prática avaliativa, ou seja, classificava-se o aluno entre os seus pares. Assim, "[...] no final do ano, realizavam-se exames [...] que atribuíam aos alunos conceitos de 'reprovado' e 'aprovado com distinção' - marcas distintivas dos alunos, no interior e no exterior da escola" (GALVÃO, 2001, p. 133).

\section{ASPECTOS PEDAGÓGICOS DO GRUPO ESCOLAR NO MUNICÍPIO DE CRUZEIRO DO SUL - ACRE}

De acordo com a investigação realizada, constatamos que a implantação do grupo escolar no município de Cruzeiro do Sul foi uma conquista significativa, que tinha como meta principal atender a população da região do Vale do Juruá, possibilitando o desenvolvimento social e cultural do lugar. 
De acordo com os dados coletados na entrevista e no livro de ata, a clientela atendida no grupo escolar, abrangia todos os níveis socioculturais, uma vez que todos tinham como objetivo comum se escolarizar. Uma das grandes dificuldades da instituição correspondia à falta de materiais e de recursos didáticos, ainda assim os professores buscavam formas de superar essas dificuldades e realizar seu trabalho, contribuindo para o desenvolvimento do aluno.

De acordo com as participantes da entrevista, as metodologias utilizadas envolviam principalmente a utilização da cartilha de alfabetização, palitos, tampas e sementes. Isso demonstra que, apesar das dificuldades, os professores buscavam estratégias metodológicas diversas na tentativa de favorecer a aprendizagem dos alunos. Quanto à relação entre professor e aluno, uma participante ressaltou que havia muito respeito, embora houvesse os castigos, como a palmatória, que segundo a mesma, visava manter a disciplina e o aprendizado dos alunos.

No grupo escolar, de acordo com as participantes, apesar de haver uma boa harmonia entre professor e aluno, existia um disciplinamento em relação ao comportamento e aprendizagem. Para Michel Foucault (1979), a escola pode ser compreendida como uma instituição disciplinar, uma vez que é entrelaçada por relações de saber e poder que põem em circulação mecanismos de disciplinarização, vigilância e punição com o intuito de atingir os objetivos educativos. Essa relação de saber e poder, destacada por Foucault, era retratada no grupo escolar Barão do Rio Branco, uma vez que, segundo as participantes, se os alunos não se enquadrassem nas regras ou não atingissem os resultados esperados nas avaliações, eram submetidos aos castigos. $\mathrm{Na}$ instituição essa era uma forma de manter a ordem, a aprendizagem e o disciplinamento, autorizado socialmente e permitido por pais e responsáveis.

Bezerra (2015), ao discorrer sobre os princípios disciplinares impostos pela Escola Normal de Cruzeiro do Sul, deixa evidente que tais princípios eram comungados com a família e a sociedade em geral, assim as normas e valores transmitidos pela instituição "[...] expandiam-se para o âmbito familiar, posto que a Escola se impunha como a instituição de formação por excelência [...]" (BEZERRA, 2015, p. 53). Os valores morais não podiam fugir da organização dos grupos escolares, afinal essas instituições tinham sido pensadas como templos de civilização e de moralização do cidadão republicano. "Concebidas e construídas como verdadeiros templos do saber, encarnavam, simultaneamente, todo um conjunto de saberes, de projetos políticopedagógicos, e punham em circulação o modelo definitivo da educação do século XIX: o das escolas seriadas" (VIDAL, FARIA FILHO, 2005, p. 53).

Nesse novo modelo de escola, valores como aqueles inerentes ao patriotismo podem ser observados não só na organização didática e disciplinar, mas inclusive, nos nomes dados às instituições, como é o caso do grupo escolar, estudado nesta pesquisa. Sobre esses valores, Souza (1998) ressalta que um aspecto interessante que rondou os grupos escolares foi a perpetuação da memória política brasileira, surgindo no período de 1894 a 1910 a figura do patrono escolar, uma personalidade nacional que havia, geralmente, ocupado cargos políticos, tais como: presidente do estado, secretários, deputados, entre outros. Tais "heróis nacionais" davam nomes às escolas ou recebiam outras honrarias. "Instituía-se, dessa forma, a figura do "patrono", personalidade a ser enaltecida e cultuada por professores, alunos e a sociedade, especialmente nas datas de comemoração do aniversário da escola" (SOUZA, 1998, p. 134). Com esse enaltecimento, 
a memória republicana ficava eternizada em forma de homenagem nos espaços de ensino, sobretudo nos grupos escolares, como é o caso da instituição aqui investigada, Barão do Rio Branco.

Ao comparar a realidade da época com a atual, constatamos diferenças em relação à formação de professores, pois, no grupo escolar Barão do Rio Branco em Cruzeiro do Sul, o modo de ingresso na profissão docente, inicialmente se constituía através de indicação. Todavia, segundo Souza (1998), esta não era uma especificidade do município, uma vez que em outras localidades, especialmente nos primeiros tempos dos grupos escolares, isso ocorria comumente. Mesmo assim, as participantes destacaram que, para ser docente no grupo escolar, exigia-se preparação e competência por parte dos professores. Em Cruzeiro do Sul, por se situar numa região de difícil acesso, a formação docente era precária e demorou a se consolidar. Em outras regiões do país, no mesmo período, não se admitia mais a prática de professores sem qualificação comprovada pelo diploma da escola Normal.

Notamos que a implantação do grupo escolar foi um passo decisivo para investimentos na área educacional no município de Cruzeiro do Sul, mas demonstrava a necessidade de haver maiores investimentos no ensino, através da ampliação de vagas em diversos níveis de escolarização para atender às demandas existentes, de modo que a população pudesse, enfim, ter garantido seu direito à educação.

\section{CONSIDERAÇÕES FINAIS}

Através desta investigação realizada com o uso da entrevista semiestruturada e de documentos escolares, foi possível compreender de forma mais efetiva o processo de criação e de funcionamento do referido grupo escolar no município de Cruzeiro do Sul$A C$, bem como a sua contribuição e importância na oferta do ensino à população. $O$ grupo visava, principalmente, atuar na redução do índice de analfabetismo existente na cidade, estando voltado ainda aos interesses políticos e econômicos, tendo em vista o reconhecimento social de que a escolaridade era essencial para o exercício político e econômico do indivíduo na sociedade.

Vimos que, mesmo diante das dificuldades existentes, tanto em relação à falta de vagas para atender a população em idade escolar, quanto a ausência de materiais pedagógicos e didáticos, acrescida da falta de infraestrutura adequada, os professores do grupo escolar buscaram desenvolver um trabalho pedagógico em prol da aprendizagem e da alfabetização dos alunos. Desse modo, havia o envolvimento dos funcionários e dos professores para que houvesse resultados mais satisfatórios. Foi possível perceber ainda que a contratação dos professores, muitas vezes se dava através de indicação por intermédio de prestígio e status social.

A implantação do grupo escolar no município de Cruzeiro do Sul apresentou como meta principal atender à demanda educacional da região, que sofria com a inexistência de instituições que oferecessem condições físicas e pedagógicas adequadas ao atendimento educacional da população em idade escolar. $O$ espaço escolar era diferenciado em relação ao modelo da maioria das instituições existentes no município, o que dava ao grupo escolar e aos profissionais que ali atuavam, certo status social e 
BEZERRA, M. I.da S.; COSTA, A. L. de O.

autoridade, emanada do prestígio social que tais instituições adquiriram em outras regiões do país.

Apesar de haver uma aparente harmonia entre professor e aluno, existia um disciplinamento em relação ao comportamento e aprendizagem dos alunos, que visava enquadrá-los nas normas impostas pelo grupo. O grupo escolar Barão do Rio Branco foi uma ação significativa para o atendimento educacional da população cruzeirense e adjacências, que ampliava as possibilidades de acesso à educação primária e de qualidade, essencial para a efetivação da cidadania dos indivíduos. Mesmo com esta atuação estratégica, a exemplo de muitas outras instituições congênitas, o grupo escolar no mencionado município teve sua história marcada por retrocessos e descontinuidades, sofrendo com o descaso das autoridades no que diz respeito à escassez de material didático, pedagógico e estrutural.

Artigo recebido em: 09/07/2020

Artigo aprovado para publicação em: 13/10/2020

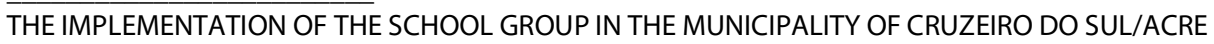

ABSTRACT: This study aims to analyze the implementation of the Barão do Rio Branco school group in the municipality of Cruzeiro do Sul-Acre, highlighting the institution's contributions to the socio-cultural development of the local population. The qualitative approach was used, through bibliographic, documentary and field research, with the use of semi-structured interviews. The results show that the implementation of the school group in the municipality of Cruzeiro do Sul, had as main goal to meet the educational demand of the region, which suffered from the lack of institutions that offered physical and pedagogical conditions to the school-age population. Even so, it is concluded that this institution suffered the neglect of the State authorities, regarding the lack of didactic and pedagogical materials.

KEYWORDS: History of education. School group. Primary school.

\section{LA IMPLANTACIÓN DEL GRUPO ESCOLAR EN EL MUNICIPIO DE CRUZEIRO DO SUL/ACRE:} CONTRIBUICIONES

RESUMEN: El presente estudio tiene como objetivo analizar la implantación del grupo escolar Barão do Rio Branco en el municipio de Cruzeiro do Sul-Acre, resaltando las contribuciones de la institución para el desarrollo sociocultural de la población local. Se utilizó el abordaje cualitativo, por medio de las investigaciones bibliográfica, documental y de campo, con el uso de la entrevista semiestructurada. Los resultados evidencian que la implantación del grupo escolar en el municipio de Cruzeiro do Sul, tuvo como meta principal atender la búsqueda educacional de la región, que sufría con la inexistencia de instituciones que ofrecen condiciones físicas y pedagógicas a la población en edad escolar. Aún así, esta institución sufrió la indiferencia de las autoridades del Estado, cuanto a la falta de materiales didácticos y pedagógicos.

PALABRAS-CLAVE: Historia de la educación. Grupo escolar. Enseñanza primaria. 


\section{REFERÊNCIAS}

LIVRO DE ATA DE MATRÍCULA. Escola Barão do Rio Branco. Cruzeiro do Sul, Acre. 1978.

LIVRO DE ATA DE PROMOÇÃO. Escola Barão do Rio Branco. Cruzeiro do Sul, Acre. 1919 a 1947.

BEZERRA, M. I. A Escola Normal Regional de Cruzeiro do Sul: tecendo memórias e histórias sobre a formação religiosa católica alemã na Amazônia acriana (1947-1965). Dissertação de mestrado. Programa de pós-graduação em Educação da Universidade Federal Fluminense: Niterói/RJ, 2010.

BEZERRA, M. I. Formação docente institucionalizada na Amazônia acriana: da Escola Normal Regional à Escola Normal Padre Anchieta (1940-1970). Tese de doutorado. Programa de pós-graduação em Educação da Universidade Federal Fluminense: Niterói/RJ, 2015.

CARVALHO, M. Reformas da instrução pública. In: LOPES, Eliana et al. (orgs). 500 anos de educação no Brasil. Belo Horizonte: Autêntica, 2003.

FOUCAULT, M. Microfísica do Poder. Trad. Roberto Machado. Rio de Janeiro, Graal, 1979.

GALVÃO, A. M. "A Palmatória era sua vara de condão": Práticas escolares cotidianas (1890-1920). In: FARIA FILHO, Luciano Mendes de (org). Modos de ler, formas de escrever: estudos de história da leitura e da escrita no Brasil. 2, ed. Belo Horizonte: Autêntica, 2001.

LEITÃO, B. J. M. Avaliação qualitativa e quantitativa numa biblioteca universitária. Niterói: Intertexto, 2005.

LUDKE, M.; ANDRÉ, M. Pesquisa em Educação: abordagens qualitativas. São Paulo: EPU/LTDA, 1986.

SOUZA, R. F. Templos de civilização: a implantação da escola primária graduada no estado de São Paulo (1890-1910). São Paulo: Editora da UNESP, 1998.

SOUZA, R. F. O direito a educação: lutas populares pela escola em Campinas. Campinas: Editora da Unicamp/ CMU, 1998.

SOUZA, R. F. Lições da escola primária. In: SAVIANI, Demerval. et al. O Legado educacional do século XX no Brasil. Campinas, SP: Autores Associados, 2004. 
BEZERRA, M. I.da S.; COSTA, A. L. de O.

SOUZA, R. M. A cultura material escolar da Deutsche Schule. Revista Brasileira de História da Educação. n. 14, mai./ago. 2007.

VIDAL, D. G; FARIA FILHO, L. M. de. Os tempos e os espaços escolares no processo de institucionalização da escola primária no Brasil. As lentes da História: estudos de história e historiografia da educação no Brasil. Campinas: 2005.

Maria IrINILDA da Silva BezerRa: Professora Adjunta da Universidade Federal do Acre/Campus Floresta, Cruzeiro do Sul - Acre - Brasil. Docente do Programa de PósGraduação em Ensino de Humanidades e Linguagens - PPEHL. Centro de Educação e Letras. Doutora em Educação pela Universidade Federal Fluminense (UFF). Graduada em Pedagogia. Membro do Grupo de Pesquisa do CNPq: Investigação Docente e Diversidades (GRIDD/UFAC).

Orcid: http://orcid.org/0000-0002-2572-414X

E-mail: iribezerra@gmail.com

Ademárcia lopes de Oliveira Costa: Professora Adjunta da Universidade Federal do Acre/Campus, Rio Branco - Acre - Brasil. Docente do Programa de Pós-Graduação em Educação - PPGE. Docente do Programa de Pós-Graduação em Ensino de Humanidades e Linguagens - PPEHL. Centro de Educação, Letras e Artes. Doutora em Educação pela Universidade Federal do Rio Grande do Norte/UFRN. Graduada em Pedagogia. Membro do Grupo de Pesquisa do CNPq: Grupo de Estudos e Pesquisas em Política, Gestão, Trabalho e Formação Docente - GEPPEAC

Orcid: http://orcid.org/0000-0001-9570-6660.

E-mail: ademarciacosta@gmail.com

Este periódico utiliza a licença Creative Commons Attribution 3.0, para periódicos de acesso aberto (Open Archives Iniciative - OAI). 